\title{
Maternal Supplementation of Vitamin D during Lactation to Support Infant Vitamin D Needs: A Systematic Review
}

\author{
Kelly Schossow ${ }^{1}$, Alena M. Clark ${ }^{2}$, Mary A. Harris ${ }^{3 *}$ \\ ${ }^{1}$ Jefferson County Public Health, Lakewood, CO, USA \\ ${ }^{2}$ Department of Nutrition and Dietetics, University of Northern Colorado, Greeley, CO, USA \\ ${ }^{3}$ Department of Food Science and Human Nutrition, Colorado State University, Fort Collins, CO, USA \\ Email:k.schossow@comcast.net, alena.clark@unco.edu, ‘mary.harris@colostate.edu
}

How to cite this paper: Schossow, K., Clark, A.M. and Harris, M.A. (2018) Maternal Supplementation of Vitamin D during Lactation to Support Infant Vitamin D Needs: A Systematic Review. Open Journal of Pediatrics, 8, 255-272.

https://doi.org/10.4236/ojped.2018.83027

Received: July 13, 2018

Accepted: September 8, 2018

Published: September 11, 2018

Copyright $\odot 2018$ by authors and Scientific Research Publishing Inc. This work is licensed under the Creative Commons Attribution International License (CC BY 4.0). http://creativecommons.org/licenses/by/4.0/

\begin{abstract}
Human milk is generally considered to be insufficient in vitamin D. However, research completed in the 1980s showed that the vitamin D content of human milk is directly related to maternal serum vitamin $\mathrm{D}$ levels and therefore may potentially be adequate if the mother's vitamin D levels are sufficient. Approximately one-third of the adult population, which includes breastfeeding women, in the United States have vitamin D insufficiency or deficiency. Among infants, $90.4 \%$ of breastfed infants are vitamin D deficient compared to $15.4 \%$ of formula fed infants. The American Academy of Pediatrics (AAP) has therefore recommended all breastfed infants be directly supplemented with 400 IU per day of vitamin D to decrease the risk of vitamin D insufficiency and rickets. According to the AAP, compliance rates with this recommendation ranges between $2 \%-36 \%$. Because the recommendation to supplement may undermine breastfeeding, many pediatricians do not inform their patients of the need to supplement. Additionally, some parents are concerned about directly supplementing their infant as risks may include allergic reactions to the ingredients, aspiration pneumonia, accidental overdose, and changes in intestinal flora and $\mathrm{pH}$ which may compromise the immune benefits of human milk. A literature review was conducted to examine the effect of maternal supplementation with vitamin D during lactation on human milk vitamin $\mathrm{D}$ content and maternal and infant serum vitamin $\mathrm{D}$ levels. Although there is no current consensus regarding dosage and timing of maternal vitamin D supplementation, the literature suggests that high-dose vitamin D supplementation of the lactating mother is as effective at maintaining infant vitamin D levels as direct infant supplementation, while also correcting the mother's vitamin D deficiency.
\end{abstract}




\section{Keywords}

Vitamin D, Breastfeeding, Human Milk, Infant, Vitamin Supplements

\section{Introduction}

Vitamin D is a steroid hormone which is naturally synthesized in the deep skin layers from 7-dehydrocholesterol when exposed to ultraviolet B wavelengths [1] [2] [3] [4]. Ninety percent of the vitamin D in non-supplemented individuals' bodies arises from natural synthesis in response to sunlight [5] [6]. Vitamin D is found in a limited number of foods including fortified milk or juice, egg yolk, liver, and fatty fish [2] [3] [5] [6] [7] [8]. Based upon results of the National Health and Nutrition Examination Survey (NHANES) 2005-2006, estimated total vitamin D availability in adult females ranges from 144 to 276 IU/day [8] resulting in low serum levels of 25-hydroxyvitamin D (25(OH)D) [5] While vitamin D has historically been thought to be primarily responsible for calcium homeostasis and bone health, new research is showing that vitamin $\mathrm{D}$ may also be important in immunomodulation, regulation of cell growth, and cardiovascular health [5]. Although $\mathrm{D}_{3}$ is the preferred form, as it is more effective in increasing serum $25(\mathrm{OH})$ D levels, vitamin $\mathrm{D}_{2}$ is often used in fortified foods.

There is a lack of consensus on vitamin D levels of sufficiency, insufficiency, and deficiency as a scientific committee process has not been established to define these levels [1] [8]. This is exacerbated by studies finding that levels once considered "normal" may actually be insufficient based upon current evidence [7]. The Institute of Medicine (IOM), based on a review of data, set the following guidelines for these levels: [8] (Table 1).

Several studies reported that 25(OH)D levels must exceed $32 \mathrm{ng} / \mathrm{mL}$ to maximize skeletal integrity. The Endocrine Society issued clinical practice guidelines in 2011 stating that the desirable serum concentration of $25(\mathrm{OH}) \mathrm{D}$ is greater than $75 \mathrm{nmol} / \mathrm{L}(30 \mathrm{ng} / \mathrm{mL})$ to maximize the effect on calcium, bone, and muscle metabolism [8].

Using the IOM definitions, results from the National Health and Nutrition Examination Surveys (NHANES) 2001-2006 showed that two-thirds of the

Table 1. Institute of Medicine definition of vitamin D status.

\begin{tabular}{|c|c|c|}
\hline $\mathrm{nmol} / \mathrm{L}$ & $\mathrm{ng} / \mathrm{mL}$ & Vitamin D Status \\
\hline$<30$ & $<12$ & $\begin{array}{l}\text { Associated with vitamin } \mathrm{D} \text { deficiency, leading to rickets in infants and } \\
\text { children and osteomalacia in adults }\end{array}$ \\
\hline 30 to $<50$ & 12 to $<20$ & $\begin{array}{l}\text { Generally considered inadequate for bone and overall health in healthy } \\
\text { individuals }\end{array}$ \\
\hline$\geq 50$ & $\geq 20$ & $\begin{array}{l}\text { Generally considered adequate for bone and overall health in healthy } \\
\text { individuals }\end{array}$ \\
\hline$>125$ & $>50$ & $\begin{array}{l}\text { Emerging evidence links potential adverse effects to such high levels, } \\
\text { particularly }>150 \mathrm{nmol} / \mathrm{L}(>60 \mathrm{ng} / \mathrm{mL})\end{array}$ \\
\hline
\end{tabular}


population had sufficient vitamin $\mathrm{D}$; one-quarter were insufficient; and eight percent were deficient [9]. A South Korean study assessed vitamin D deficiency among infants and noted that $48.7 \%$ had insufficient 25(OH)D levels [10]. Among breastfed infants, vitamin $\mathrm{D}$ deficiency prevalence was significantly higher at $90.4 \%$ than formula fed infants, who had a prevalence of $15.4 \%$. Mean serum $25(\mathrm{OH}) \mathrm{D}$ of breastfed infants was significantly lower compared to formula fed infants, even when vitamin D was sufficient $(\mathrm{p}<0.001)$.

Vitamin $\mathrm{D}$ deficiency rates have increased with the modern lifestyle characterized by decreased sun exposure related to urbanization, increased indoor activities, and use of sunscreen [7]. Caucasian individuals require 10 - 12 minutes of full body sun exposure to synthesize 10,000-20,000 IU of vitamin D; in comparison, an individual with dark skin would need $60-72$ minutes of exposure to synthesize the same amount of vitamin D [6] [7]. During the winter months, individuals living at a latitude above $40^{\circ}$ do not synthesize an adequate amount of vitamin D, regardless of exposure [7].

Only small amounts of $25(\mathrm{OH}) \mathrm{D}$ pass from the maternal circulation to human milk [1]. Instead, vitamin D is passed into human milk as cholecalciferol (vitamin $\mathrm{D}_{3}$, the parent form of $\left.25(\mathrm{OH}) \mathrm{D}\right)$ [1]. It has been shown that $20 \%-30 \%$ of maternal vitamin $\mathrm{D}$ is expressed in human milk compared to only $1 \%$ of maternal 25(OH)D [6] [7] [11].

The Institute of Medicine (IOM) and the American College of Obstetrics and Gynecologists (ACOG) recommends 600 IU of vitamin D daily for all adults, including pregnant and lactating women (increased in 2008 from the Adequate Intake of 200 IU per day, which was previously arbitrarily set) [1] [8] [12]. The Endocrine Society shares this recommendation but suggest that 1500 to $2000 \mathrm{IU}$ may be necessary to maintain adequate serum $25(\mathrm{OH}) \mathrm{D}$ [1]. The Recommended Dietary Allowance (RDA) for infants 0 - 12 months, as set by the Food and Nutrition Board (FNB) at the IOM of the National Academies, is 400 IU [8].

The Tolerable Upper Intake Level for vitamin D has been set at $4000 \mathrm{IU}$ in pregnancy and lactation, and at $1000 \mathrm{IU}$ for infants [8]. However, most reports suggest a toxicity threshold for vitamin D between 10,000 and 40,000 IU per day [3] [8]. Symptoms of toxicity are unlikely at daily intakes below 10,000 IU per day; however, the Food and Nutrition Board suggests that even lower vitamin D intakes may have adverse health effects over time, based on national survey data, observational studies, and clinical trials [8]. The No Observed Adverse Effect Level (NOAEL) has been set at 10,000 IU daily by the IOM [4] [6].

Setting adequacy levels is difficult since the relationship between serum $25(\mathrm{OH}) \mathrm{D}$ levels and vitamin $\mathrm{D}$ intake is non-linear, for reasons that are not entirely clear [8]. Doses greater than or equal to 1000 IU per day are associated with a $1 \mathrm{nmol} / \mathrm{L}$ rise in serum $25(\mathrm{OH}) \mathrm{D}$ per $40 \mathrm{IU}$ of intake [8]. Doses up to 600 IU per day are associated with a $2.3 \mathrm{nmol} / \mathrm{L}$ increase in serum 25(OH)D per 40 IU consumed [8].

Traditionally, it has been thought that the vitamin D content of human milk was inadequate to meet infant vitamin D needs [1] [8] [13]. Vitamin D activity 
in human milk has been found to range between five to 80 IU/L [3] [4] [13]. However, research completed in the 1980s showed that vitamin D content of human milk is directly related to maternal serum vitamin D levels and, therefore has the potential to be adequate when mothers' vitamin $\mathrm{D}$ levels are sufficient [1] [7] [8] [11] [13].

In infants and young children, long-term vitamin $\mathrm{D}$ deficiency leads to rickets [5]. While rickets were thought to be eradicated in the United States, recent reports show that prevalence is rising once again [2] [12]. A review from the United States included 166 patients with nutritional rickets during the time period of 1986-2003; 96\% of the children with rickets were breastfed. Therefore, the American Academy of Pediatrics (AAP) recommends that all breastfed infants receive $400 \mathrm{IU}$ of oral vitamin D daily starting at birth [1] [4] [6] [7] [8] [11] [12]. This recommendation is a result of poor transfer of vitamin D from the maternal circulation into human milk in addition to the guidance to minimize sun exposure to infants up to six months of age [1] [4] [6] [7] [8] [12].

Many parents do not supplement their infants according to the AAP recommendation [6] [11]. Of 1140 exclusively breastfed infants, only $15.9 \%$ received any vitamin D supplements [6]. Other reports show compliance rates between $2 \%-36 \%$ [2] [4] [13]. Only $5 \%$ of those with rickets are reported to have received vitamin D supplementation [5] [6]. This guideline may undermine breastfeeding success by implying that human milk is an inadequate source of complete nutrition for infants [6]. In fact, $36.4 \%$ of surveyed pediatricians in Seattle, WA chose not to recommend vitamin D supplements to breastfed infants due to concerns that parents would cease breastfeeding [6]. There is also some concern surrounding direct supplementation of the infant. Risks are currently unclear, but may include allergic reactions to the ingredients, aspiration pneumonia, accidental overdose, and changes in intestinal flora and $\mathrm{pH}$ may compromise. Given these concerns, the purpose of this review was to evaluate the impact of high-dose maternal vitamin D during lactation on human milk content and infant vitamin D status.

\section{Methods}

\subsection{Data Source and Searches}

Medline and Google scholar were searched from January 2003 through May 2018. Earlier studies were excluded due to the unacceptably large variance in vitamin D assays prior to this time [13]. The key words and MESH terms used to gather and classify the research both independently and in combination were maternal, breastfeed(ing) or lactation, Vitamin D, dietary supplements, milk/human, cholecalciferol, infants/physiologic phenomena. References found in articles were examined to identify any additional articles but no studies within the search delimitations were identified. The search was delimited to English language and humans. The search strategies for breastfeed ${ }^{*}$ and vitamin $\mathrm{D}$ (or Vitamin D status or cholecalciferol) and milk/human and infant/physiologic phe- 
nomena yielded 173 articles. Substitution of lactation instead of breastfeed ${ }^{*}$ yielded 184 articles; all but 11 were duplicates. Adding maternal to the search strategy did not alter the number of titles retrieved. Adding the term dietary supplements did not improve the final yield.

Abstracts were reviewed for eligibility. Complete articles of those accepted were independently reviewed by two investigators (KS and MAH) and accepted if they met the inclusion criteria of maternal supplementation during lactation, included data on vitamin D status of infants, evaluated the effect of maternal dose and exclusive breastfeeding or minimal, and documented, formula supplementation. Articles were excluded if they were not published in English, full text was unavailable ( 1 article), did not evaluate infant vitamin $\mathrm{D}$ status in relation to maternal supplementation with vitamin $\mathrm{D}$, evaluated more than one micronutrient or were commentaries on previous studies. Articles were also excluded if they examined vitamin D supplementation during pregnancy since the association between vitamin $\mathrm{D}$ supplementation during pregnancy and offspring vitamin D status and outcomes has been the subject of a current systematic review and meta-analysis [14].

\subsection{Study Selection}

Of the 184 articles which were identified, 86 articles titles were outside of the inclusion criteria, 98 were considered for review of abstracts. This review yielded 11 studies that met inclusion criteria with a variety of strengths, weaknesses, and overall contribution to the present research question. The PRISMA diagram is presented in Figure 1.

\subsection{Assessment of Quality}

Quality was evaluated using the Academy of Nutrition and Dietetics EAL Quality Assessment Checklists [15].

An overall positive rating indicates that criteria were adequately addressed. A negative rating was assigned if the criteria were not adequately addressed and a neutral rating was assigned if indicators were mixed and the study design was neither exceptionally strong nor exceptionally weak. The checklists include 10 validity criteria: clearly stated research question (procedures, outcomes, inclusion/exclusion criteria) potential bias, comparability of groups, handling of withdrawn subjects, appropriate statistical analysis and conclusions supported by the results. The quality checklists are shown in Table 2 and Table 3.

\section{Results}

A summary of study populations, interventions and outcomes and overall quality ratings are shown in Table 4.

\subsection{Interventions with Vitamin $\mathrm{D}_{2}$}

Vitamin $\mathrm{D}_{2}$ supplementation was chosen in several studies in an effort to better 


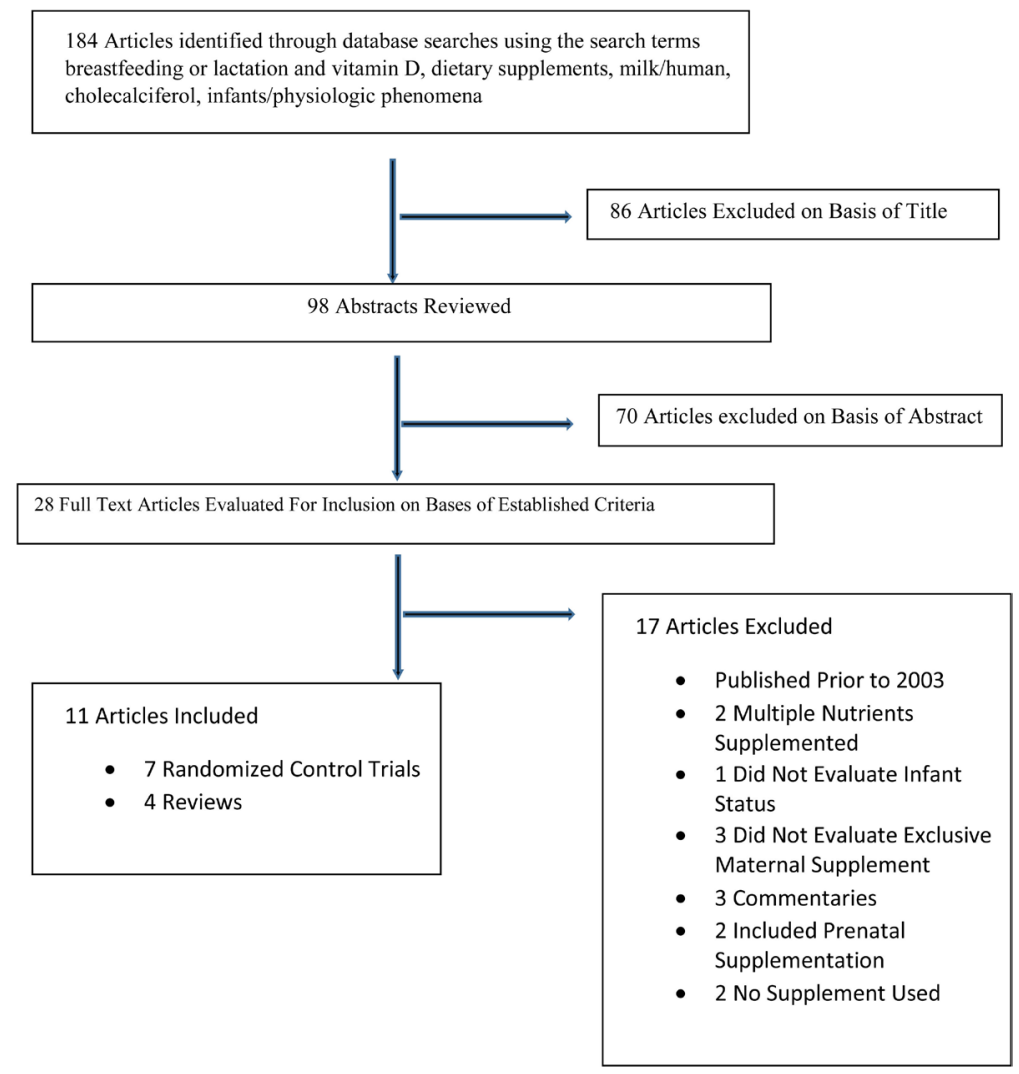

Figure 1. PRISMA diagram.

Table 2. Quality criteria checklist intervention studies.

\begin{tabular}{|c|c|c|c|c|c|c|c|}
\hline Validity Question & Nalk, 2017 & $\begin{array}{l}\text { Wheeler, } \\
2016\end{array}$ & Hollis, 2015 & Basile, 2006 & $\begin{array}{l}\text { Wagner, } \\
2006\end{array}$ & $\begin{array}{l}\text { Oberhelman, } \\
2013\end{array}$ & Hollis, 2004 \\
\hline 1. Was research question stated clearly? & Yes & Yes & Yes & Yes & Yes & Yes & Yes \\
\hline 2. Was selection of study subjects free from bias? & Yes & Yes & Yes & No & No & Yes & Yes \\
\hline 3. Were study groups comparable? & Yes & Yes & Yes & Yes & Yes & Yes & Yes \\
\hline $\begin{array}{l}\text { 4. Was method of handling withdrawals } \\
\text { described? }\end{array}$ & $\mathrm{n} / \mathrm{a}$ & No & $\mathrm{n} / \mathrm{a}$ & No & Yes & $\mathrm{n} / \mathrm{a}$ & $\mathrm{n} / \mathrm{a}$ \\
\hline $\begin{array}{l}\text { 5. Was blinding used to prevent introduction of } \\
\text { bias? }\end{array}$ & Yes & Yes & Yes & Yes & Yes & No & No \\
\hline $\begin{array}{l}\text { 6. Were intervention and comparison described } \\
\text { in detail? }\end{array}$ & Yes & Yes & Yes & Yes & Yes & Yes & Yes \\
\hline $\begin{array}{l}\text { 7. Were outcomes clearly defined and the } \\
\text { measurements valid and reliable? }\end{array}$ & Yes & Yes & Yes & Yes & Yes & Yes & Yes \\
\hline $\begin{array}{l}\text { 8. Was the statistical analysis appropriate for the } \\
\text { study design and type of outcome indicators? }\end{array}$ & Yes & Yes & Yes & Yes & Yes & Yes & Yes \\
\hline $\begin{array}{l}\text { 9. Are conclusions supported by results with } \\
\text { biases and limitations taken into consideration? }\end{array}$ & Yes & Yes & Yes & Yes & Yes & Yes & Yes \\
\hline $\begin{array}{l}\text { 10. Is bias due to study's funding or sponsorship } \\
\text { unlikely? }\end{array}$ & Yes & Yes & Yes & Yes & Yes & Yes & Yes \\
\hline
\end{tabular}

track the effects of supplementation, as contribution from other sources is unlikely [3] [12]. Hollis and Wagner examined two groups of exclusively breastfeeding mother-infant pairs $(n=18)$ [12]. In the first intervention group, mothers 
Table 3. Quality criteria checklist review studies.

\begin{tabular}{|c|c|c|c|c|}
\hline Validity Question & Haggerty, 2011 & Taylor, 2008 & Thiele, 2013 & Dawodu, 2012 \\
\hline 1. Was the question for the review clearly focused? & Yes & Yes & Yes & Yes \\
\hline $\begin{array}{l}\text { 2. Was the search strategy used to locate studies comprehensive? Were } \\
\text { databases and search terms described? }\end{array}$ & Yes & No (unclear) & Yes & No (unclear) \\
\hline 3. Were explicit methods used to select studies? & No (unclear) & No (unclear) & Yes & No \\
\hline $\begin{array}{l}\text { 4. Was there a specified and valid methods for appraisal of quality and } \\
\text { validity of studies? }\end{array}$ & No & No (unclear) & Yes & No \\
\hline 5. Were specific treatments, interventions, exposures described? & No & No (unclear) & Yes & Yes \\
\hline 6. Was the outcome of interest clearly indicated? & Yes & Yes & Yes & Yes \\
\hline $\begin{array}{l}\text { 7. Were processes for data abstraction, synthesis and analysis described and } \\
\text { applied consistently? Was variation among findings analyzed? Were } \\
\text { heterogeneity issues considered? If studies aggregated for meta-analysis, } \\
\text { were procedures described? }\end{array}$ & No (unclear) & No (unclear) & Yes & No (unclear) \\
\hline 8. Were results clearly presented in narrative and/or quantitative terms? & Yes & Yes & Yes & Yes \\
\hline $\begin{array}{l}\text { 9. Are conclusions supported by results with biases and limitations taken } \\
\text { into consideration? }\end{array}$ & No & No & No & No \\
\hline 10. Is bias due to study's funding or sponsorship unlikely? & Yes & Yes & Yes & Yes \\
\hline
\end{tabular}

Table 4. Summary of evidence.

\begin{tabular}{|c|c|c|c|c|c|}
\hline Citation & $\begin{array}{l}\text { Study } \\
\text { Design }\end{array}$ & $\begin{array}{l}\text { Quality } \\
\text { Rating }\end{array}$ & $\begin{array}{l}\text { Population/ } \\
\text { Sample }\end{array}$ & $\begin{array}{l}\text { Intervention/ } \\
\text { Comparisons }\end{array}$ & Outcomes \\
\hline
\end{tabular}

Nalk, Nalk P., Faridi,

M.M.A., Batra, P.,

Madhu, S.V. Oral

Supplementation of

Parturient Mothers

with Vitamin D and its

Effect on 25OHD

Status of Exclusively

Breastfed Infants at 6

Months of Age: A

Double-blind

Randomized Placebo

Controlled Trial. 2017,

Breastfeed Med.

12:621-9.

Reference [19]

Wheeler BJ, Taylor BJ,

Herbison P, et al.

High-Dose Monthly

Maternal

Cholecalciferol

Supplementation during Breastfeeding

Affects Maternal and

Infant Vitamin D

Status at 5 Months

Postpartum: A

Randomized

Controlled Trial. J

Nutr. 2016,

146:1999-2006.

Reference [2]

Group 1: Maternal

supplement of 600,000

$\mathrm{IU}$ vitamin $\mathrm{D}_{3}$ in 10

divided doses in early Maternal 25(OH)D levels after 6 months of study were postpartum

100 Randomized exclusively Controlled Positive breastfeeding Trial mother/infant pairs in Turkey oup 2: Placebo Measurement of $(29.29 \pm 14.67 \mathrm{ng} / \mathrm{m})$ in those fed by supplemented maternal and infant mothers compared to $15.73 \pm 17.73 \mathrm{ng} / \mathrm{mL}$ in controls. $5(\mathrm{OH}) \mathrm{D}$ at initiation of After 6 months of exclusive breastfeeding only one study and at 6 months mother and four infants had serum $25(\mathrm{OH})$ D levels < of age. Radiographically determined and biochemical indices (Alkaline phosphatase) in infants
87 exclusively breastfeeding

Randomized Controlled Positive Trial mother/infant pairs in New Zealand
$11 \mathrm{ng} / \mathrm{ml}$ in the supplemented group $(\mathrm{n}=53)$ vs 9 mothers and 25 infants $(n=57)$ in the control. 2 infants in each group developed clinical rickets. greater $(40.3 \pm 21.6 \mathrm{ng} / \mathrm{mL})$ in supplemented vs $(22.9 \pm$ $20.18 \mathrm{ng} / \mathrm{mL}$ ) in controls. Infant levels were also higher e)

\section{Group 1: Placebo} Group 2: 50,000 IU vitamin $\mathrm{D}_{3}$ per month Group 3: 100,000 IU vitamin $\mathrm{D}_{3}$ per month
Maternal supplementation with 50,000 IU and 100,000 IU vitamin D resulted in significantly higher serum 25(OH)D concentrations at study end compared to placebo ( $\mathrm{p}=0.043 ; \mathrm{p}=0.001$, respectively). Infant change in serum $25(\mathrm{OH}) \mathrm{D}$ was not significant between groups ( $p=0.67 ; p=0.13$, respectively). $26 \%$ of mothers in the placebo group exhibited vitamin $\mathrm{D}$ deficiency, compared to $4 \%$ in the 50,000 IU group and $0 \%$ in the $100,000 \mathrm{IU}$ group at study end $(\mathrm{p}=0.002)$. Deficiency rates between infants in all groups were similar $(27 \%, 29 \%$, and $19 \%$, respectively; $\mathrm{p}=0.65)$. 


\section{Continued}

Hollis BW, Wagner CL,

Howard CR, et al.

Maternal Versus Infant

Vitamin D

Supplementation

Randomized

During Lactation: A

Randomized

Controlled Positive

Controlled Trial.

Pediatrics. 2015,

136:625-34.

Reference [16]

Basile LA, Taylor SN,

Wagner CL, Horst RL,

Hollis BW. The effect

of high-dose vitamin D supplementation on serum vitamin $\mathrm{D}$ levels and milk calcium

Randomized

concentration Trial

lactating women and

their infants.

Breastfeed Med. 2006,

1:27-35. Reference [3]

Wagner CL, Hulsey

TC, Fanning D, Ebeling

M, Hollis BW.

High-dose vitamin $\mathrm{D}_{3}$ supplementation in a

cohort of breastfeeding

mothers and their

Randomized

infants: a 6-month

Controlled Neutral

follow-up pilot study.

Breastfeed Med.

2006.1:59-70.

Reference [11]
95 exclusively/

fully

breastfeeding

mother/infant

pairs in

Charleston,

South Carolina

and Rochester,

New York

Controlled Neutral
25 fully

breastfeeding

mother-infant

pairs in South

Carolina
10 fully

lactating

mother-infant

pairs in South

Carolina (of

note, only 4

continued

breastfeeding

through the

entire study, but

intent-to-treat

included all 10

women)
Group 1: Maternal

supplement $400 \mathrm{IU}$

vitamin $\mathrm{D}_{3}$ per day;

$400 \mathrm{IU}$ vitamin $\mathrm{D}_{3}$ per

day for infants

Group 2: Maternal

supplement $2400 \mathrm{IU}$

Maternal 25(OH)D levels were significantly higher in mothers supplemented with $6400 \mathrm{IU}$ than those with ( $\mathrm{D}_{3}$; placebo for respectively). Infant $25(\mathrm{OH}) \mathrm{D}$ was similar between infants (discontinued groups at all visits $(\mathrm{p}=0.35$ at $\mathrm{V} 1, \mathrm{p}=0.10$ at $\mathrm{V} 4$, and $\mathrm{p}$ due to safety concerns, $=0.94$ at V7). Maternal supplementation with 6400 not included in IU/day is as effective at meeting infant vitamin D needs analysis)

Group 3: Maternal supplement $6400 \mathrm{IU}$ vitamin $\mathrm{D}_{3}$; placebo for infants
Group 1: Maternal supplement $400 \mathrm{IU}$ vitamin $\mathrm{D}_{3}+1600 \mathrm{IU}$ vitamin $\mathrm{D}_{2}$ supplement $400 \mathrm{IU}$ vitamin $\mathrm{D}_{3}+3600 \mathrm{IU}$ vitamin $\mathrm{D}_{2}$ Group 2: Maternal
Women in both study groups had significantly elevated circulating 25(OH)D concentrations after the 3 months of supplementation (2000 IU group: $p=0.002 ; 4000 \mathrm{IU}$ group: $\mathrm{p}=0.0008)$. Women receiving $4000 \mathrm{IU} /$ day exhibited significantly higher 25(OH)D concentrations than those in the $2000 \mathrm{IU} /$ day group $(\mathrm{p}=0.03)$. Infants experienced a significant increase in $25(\mathrm{OH}) \mathrm{D}$. Infants in the $4000 \mathrm{IU}$ group exhibited a higher $25(\mathrm{OH}) \mathrm{D}$ concentration compared to $2000 \mathrm{IU}(\mathrm{p}=0.01)$.
Group 1: Maternal supplement $400 \mathrm{IU}$ vitamin $\mathrm{D}_{3}$ /day; 300 IU/day vitamin $\mathrm{D}_{3}$ for infants

Group 2: Maternal supplement $6400 \mathrm{IU}$ vitamin $\mathrm{D}_{3}$ /day; placebo for infants (2)

The total circulating 25(OH)D levels of mothers in group 1 decreased through visit 5 ; there was a slight improvement at visits 6 and 7 that corresponded to increased outdoor activities and sun exposure (significance not provided). Mothers in group 2 had an immediate increase in $25(\mathrm{OH}) \mathrm{D}$ levels that was sustained throughout the study period (significance not provided). Despite the increased outdoor activities and an increase in sunlight exposure that paralleled group 1 , after achieving steady-state by month 3 , there was very little change in maternal $25(\mathrm{OH}) \mathrm{D}$ from months 3 to 7. Compared to group 1, the mean milk ARA in group 2 significantly increased to $873 \mathrm{IU} / \mathrm{L}$

$(\mathrm{p}<0.0003)$, which resulted in a dramatic rise in infant circulating 25(OH)D levels. This rise in infant $25(\mathrm{OH}) \mathrm{D}$ was almost identical to that in the infants receiving $300 \mathrm{IU} /$ day vitamin $\mathrm{D}_{3}$ directly via oral supplementation.

The single dose group had significantly greater maternal 25(OH)D concentrations than the daily dose Meekins ME, Fischer PR, et al. Maternal vitamin D

40 exclusively breastfeeding mother-infant pairs in Rochester, Minnesota
Group 1: Maternal supplement $150,000 \mathrm{IU}$ the single dose group, maternal $25(\mathrm{OH}) \mathrm{D}$ values vitamin $\mathrm{D}_{3}$ monthly Group 2: Maternal supplement $5000 \mathrm{IU}$ vitamin $\mathrm{D}_{3} /$ day
Controlled Positive Trial

improve the vitamin
status of breastfed infants: a randomized controlled trial. Mayo Clin Proc. 2013, peaked on day 3 , and the maximum value observed in any mother was $72 \mathrm{ng} / \mathrm{mL}$. By day 28 the increase in $25(\mathrm{OH}) \mathrm{D}$ between baseline and day 28 was $11.9+/-4.2$ $\mathrm{ng} / \mathrm{mL}$ in the single dose group and $15.0+/-5.7 \mathrm{ng} / \mathrm{mL}$ in the daily dose group $(\mathrm{p}=0.06)$. None of the mothers' serum $25(\mathrm{OH}) \mathrm{D}$ concentration remained $<20 \mathrm{ng} / \mathrm{mL}$ 


\section{Continued}

88:1378-87.

Reference [4]
Hollis BW, Wagner CL.

Vitamin D

requirements during

lactation: high-dose

maternal

supplementation as

therapy to prevent

hypovitaminosis $\mathrm{D}$ for Tria

both the mother and

the nursing infant. Am

J Clin Nutr. 2004,

80:1752S-8S.

Reference [12]
Group 1: Maternal supplement $1600 \mathrm{IU}$

18 fully breastfeeding mother-infant pairs in Charleston, South Carolina vitamin $\mathrm{D}_{2}+400 \mathrm{IU}$ vitamin $\mathrm{D}_{3}$ Group 2: Maternal supplement $3600 \mathrm{IU}$ vitamin $\mathrm{D}_{2}+400 \mathrm{IU}$ vitamin $\mathrm{D}_{3}$ Infants not supplemented

on day 28 (daily dose group $43.9+/-11.8$, range $22-71$ $\mathrm{ng} / \mathrm{mL}$; single dose group $41.2+/-8.9$, range 26 - 60 $\mathrm{ng} / \mathrm{mL}$ ). Human milk cholecalciferol concentrations mirrored serum concentrations, with peak values approximately $25 \%$ of serum values on day 1 in the single dose group. Human milk 25(OH)D was undetectable in all samples. By day 28, serum 25(OH)D had a nearly identical increase in the infants of both groups (significance not provided). By day 28, all infants achieved a serum 25(OH)D concentration $>20$ $\mathrm{ng} / \mathrm{mL}$. The increase of the infant's $25(\mathrm{OH}) \mathrm{D}$ concentration was not related to their mother's increase of $25(\mathrm{OH}) \mathrm{D}$ concentration $(\mathrm{r}=0.07, \mathrm{P}=0.64)$. No adverse events during the study were attributed to vitamin D.

No adverse events were observed from taking up to 10 times the DRI for vitamin D for lactating women for a period of 3 months. Group 1 exhibited decreased vitamin $\mathrm{D}_{3}(\mathrm{P}<0.02)$ but increased vitamin $\mathrm{D}_{2}(\mathrm{P}<$ $0.0001)$. The total circulating $25(\mathrm{OH}) \mathrm{D}$ (vitamin $\mathrm{D}_{2}$ and $\mathrm{D}_{3}$ ) increased from $27.6+/-3.3$ to $36.1+/-2.3 \mathrm{ng} / \mathrm{mL}$ $(\mathrm{P}<0.05)$. In group 2 , total circulating $25(\mathrm{OH}) \mathrm{D}$ increased from $32.9+/-2.4$ to $44.5+/-3.9 \mathrm{ng} / \mathrm{mL}(\mathrm{P}<$ 0.04). Both vitamin $\mathrm{D}_{2}$ and $\mathrm{D}_{3}$ also increased $(\mathrm{P}<0.04$ and $\mathrm{P}<0.06$, respectively). Although $25(\mathrm{OH}) \mathrm{D}_{3}$ concentrations did not differ between groups during the study period, there were significant differences between the 2 groups with respect to $25(\mathrm{OH}) \mathrm{D}_{2}$ concentrations $(\mathrm{P}<0.01)$, with higher concentrations in the $4000 \mathrm{IU}$ group. Group 1 exhibited increases in milk ARA from $35.5+/-3.5$ to $69.7+/-3.0$ IU/L (P < $0.0001)$. Group 2 exhibited increases in milk ARA from $40.4+/-3.7$ to $134.6+/-48.3$ IU/L $(\mathrm{P}<0.0001)$. Group 1 infants exhibited increases in circulating vitamin $\mathrm{D}_{3}$ and $\mathrm{D}_{2}$ concentrations $(7.9+/-1.1$ to $21.9+/-4.7$ $\mathrm{ng} / \mathrm{mL}$ and $<0.5$ to $6.0+/-1.0 \mathrm{ng} / \mathrm{mL}$, respectively) (P $<0.02$ and $\mathrm{P}<0.0007$, respectively). Total circulating $25(\mathrm{OH}) \mathrm{D}$ concentrations increased from $7.9+/-1.1$ to $27.8+/-3.9 \mathrm{ng} / \mathrm{mL}(\mathrm{P}<0.02)$. Group 2 infants exhibited vitamin $\mathrm{D}_{3}$ increases $(12.7+/-3.4$ to $18.8+/$ $4.1 \mathrm{ng} / \mathrm{mL}, \mathrm{P}<0.2)$ and vitamin $\mathrm{D}_{2}$ increases $(0.8+/-$ 0.4 to $12.0+/-1.4 \mathrm{ng} / \mathrm{mL}, \mathrm{P}<0.0001)$. Total circulating 25(OH)D concentrations increased from $13.4+/-3.3$ to $30.8+/-5.0 \mathrm{ng} / \mathrm{mL}(\mathrm{P}<0.01)$. Compared with infants in group 1, infants in group 2 exhibited higher vitamin $\mathrm{D}_{2}$ concentrations at the end of the study period $(\mathrm{P}<0.003)$.

Study 1: All mothers received $400 \mathrm{IU}$ of vitamin $\mathrm{D}_{3} /$ day Group $1+1600 \mathrm{IU}$ vitamin $\mathrm{D}_{2}$ /day. Group +3600 IU of vitamin $\mathrm{D}_{2}$ /day
Study 1: There was a significantly higher increase in maternal serum 25(OH)D levels $(\mathrm{p}<0.01)$ and directly correlated increase in infant serum 25(OH)D levels ( $p$ $<0.003$ ) in the group that received $4000 \mathrm{IU} /$ day compared to those who received $2000 \mathrm{IU} /$ day. Human milk ARA in the 4000 IU group increased significantly higher than the other group $(\mathrm{p}<0.0001)$. There were no adverse events in mothers or infants from

Med. 2011, 6:137-44.

Reference [6] 


\section{Continued}

Study 2: All mothers consuming a daily intake of vitamin D up to 10 times received $400 \mathrm{IU}$ of the daily recommended intake. Study 2: There were vitamin $\mathrm{D}_{3}$ /day. Group significantly higher increases in maternal serum 1 infants received $300 \quad 25(\mathrm{OH}) \mathrm{D}$ levels for the high-dose-supplemented IU of vitamin $\mathrm{D}_{3}$ daily; mothers than those taking 400 IU daily $(\mathrm{p}<0.0028)$. mothers received no The mean maternal 25(OH)D levels in the $6400 \mathrm{IU}$ additional supplement group rose quickly within the first month and stabilized Group 2 mothers a after 3 months. Maternal 25(OH)D levels of those received $+6000 \mathrm{IU}$ of receiving $400 \mathrm{IU}$ daily rose slightly, but still within the vitamin $\mathrm{D}_{3}$ daily. insufficient range. There was no significant difference Study 3: Group $1 \quad$ between groups with infant mean 25(OH)D. Both Maternal supplement groups of infants had increases from baseline 25(OH)D $2000 \mathrm{IU}$ vitamin means, but still at insufficient levels. Considering levels $\mathrm{D}_{2} /$ day. Group $2 \quad$ were similar, this suggests that maternal Maternal supplement supplementation of $6400 \mathrm{IU}$ of vitamin D daily is 60,000 IU $\mathrm{D}_{2}$ monthly. equally effective as supplementing the infant with 300 Infants were not IU of vitamin D daily. Human milk ARA correlated supplemented or tested with the mother's 25(OH)D level. Those taking 6400 in study 3 . IU/day showed significantly increased ARA ( $\mathrm{p}<$ Study 4: Mothers and 0.0003). There was no evidence of toxicity in either infants supplemented group, based on serum calcium, phosphorus levels, and simultaneously at urine calcium/creatinine ratios. Study 3: Lactating undefined levels. women had significantly lower baseline $25(\mathrm{OH}) \mathrm{D}$ means compared to nulliparous women $(\mathrm{p}<0.001)$. Although the serum 25(OH)D levels in lactating women increased significantly in both intervention groups ( $\mathrm{p}<0.001$ ), the $25(\mathrm{OH}) \mathrm{D}$ levels reached greater than or equal to $50 \mathrm{nmol} / \mathrm{L}$ in only $35 \%$ of the daily dosage group and $20 \%$ of the monthly intervention group. Nulliparous women had similar results for sufficient levels of $25(\mathrm{OH}) \mathrm{D}$ (36\% in the daily group and $33 \%$ in the monthly group). Monthly doses, with a spike of milk vitamin D levels within 24 hours of maternal dosing and then a rapid decrease of milk vitamin D levels, are significantly efficacious than daily dosing for maintaining adequate milk vitamin D levels. Monthly dosing may still be preferred in an extremely noncompliant patient population versus no supplementation at all. Study 4: $94 \%$ of infants were deficient at baseline. Combined maternal and infant supplementation increased the infant mean $25(\mathrm{OH}) \mathrm{D}$ levels by $33.2 \mathrm{nmol} / \mathrm{L}$. A $64 \%$ reduction of vitamin D deficiency ( $\mathrm{p}<0.0001$ ) was demonstrated without adverse effects. Mean 25(OH)D remained considerably below the insufficient level of $32 \mathrm{ng} / \mathrm{mL}$. Mean ARA at baseline was undetectable $(<20 \mathrm{IU} / \mathrm{L})$ and increased to a median vitamin D level of $50.9 \mathrm{IU} / \mathrm{L}$ after 3 months of supplementation.

Taylor SN, Wagner CL, Hollis BW. Vitamin D supplementation during lactation to support infant and mother. J Am Coll Nutr. 2008, 27:690-701. Reference [7]

$\begin{array}{lll}\text { Narrative } & \text { Negative } & 3 \text { studies } \\ \text { reviewed }\end{array}$

Study 1: Group 1: 2000 Study 1 showed equivalent vitamin D status in the 2 IU vitamin $\mathrm{D}_{3} \quad$ infant comparison groups. Maternal supplementation maternal intake, of $1000 \mathrm{IU} /$ day vitamin $\mathrm{D}_{3}$ did increase serum Group 2: $400 \mathrm{IU} \quad 25(\mathrm{OH}) \mathrm{D}$ concentrations in infants to levels considered vitamin $\mathrm{D}_{3}$ infant sufficient to avoid rickets. Study 2 found that mothers intake. experienced significant increases in total circulating Study 2: Group 1: 1600 25(OH)D concentrations and 25(OH) $\mathrm{D}_{2}$, but there IU vitamin $\mathrm{D}_{2}+400$ were decreases in $25(\mathrm{OH}) \mathrm{D}_{3}$. The significant 
Thiele DK, Senti JL, Anderson CM. Maternal vitamin D supplementation to meet the needs of the breastfed infant: a systematic review. J Hum Lac. 2013,

29:163-70.

Reference [1]
Dawodu A, Tsang RC. Maternal vitamin $\mathrm{D}$ status: effect on milk vitamin $\mathrm{D}$ content and vitamin D status of breastfeeding infants. Narrative
Review Negative $\begin{aligned} & 3 \text { studies } \\ & \text { reviewed }\end{aligned}$ Adv $*$ Nutr. 2012,

3:353-61.

Reference [5]

Systematic Review Positive 3 articles were reviewed
IU $\mathrm{D}_{3}$, Group 2: 3600 IU vitamin $\mathrm{D}_{2}+400$ IU D . $_{3}$ Study 3: Group 1: 400 IU $\mathrm{D}_{3}$ for mothers + $300 \mathrm{IU} \mathrm{D}_{3}$ for infants, Group 2: $6400 \mathrm{IU} \mathrm{D}_{3}$ for mother. improvement in maternal vitamin D status translated into increases in the vitamin D activity in the milk, but it did not reach $400 \mathrm{IU} / \mathrm{L}$. The 2000 IU group had a mean milk ARA of $69.7+/-3.0 \mathrm{IU} / \mathrm{L}$. Mothers in the 4000 IU group had a mean milk ARA of $134.6+/-48.3$ IU/L. Infants experienced a significant improvement in 25(OH)D levels in both groups, though still insufficient. Study 3 found that mothers receiving 6400 IU/day for 6 months had an increase in milk ARA from 82 to $873 \mathrm{IU} / \mathrm{L}$. This increase in vitamin D supply to the infant achieved infant vitamin D status equal to that observed with direct infant supplementation of 300 IU/day. Mothers demonstrated significant improvement in vitamin D status. No toxicity was observed in mothers or infants throughout the 6 month study period.
Study 1: Group 1

Maternal supplement 2000 IU vitamin D/day $\left(400\right.$ as $\mathrm{D}_{3}$ and 1600 as $\mathrm{D}_{2}$ ). Group 2 Maternal supplement 4000 IU/day (400 as $\mathrm{D}_{3}$ and 3600 as $\mathrm{D}_{2}$ ).

Study 2: Group 1 Maternal supplement $400 \mathrm{IU}$ vitamin $\mathrm{D}_{3} /$ day, infants received $300 \mathrm{IU}$ vitamin $\mathrm{D}_{3}$. Group 2 Maternal supplement 6400 IU vitamin $\mathrm{D}_{3}$ /day; infants received a placebo. Study 3: Group 1 Maternal supplement 2000 IU vitamin $\mathrm{D}_{2}$ /day. Group 2 Maternal supplement 60,000 IU vitamin $\mathrm{D}_{2}$ monthly. Infants received $400 \mathrm{IU}$ vitamin $\mathrm{D}_{2} /$ day.

Study 1: Group 1 Maternal supplement 2000 IU vitamin D/day. Group 2

Maternal and infant serum 25(OH)D levels increased in direct relationship to maternal vitamin $\mathrm{D}$ intake. Maternal vitamin D supplementation during lactation has an equivalent effect on infant $25(\mathrm{OH}) \mathrm{D}$ status as direct infant supplementation but also the potential to benefit both mother and child. There is no evidence to suggest that maternal vitamin $\mathrm{D}$ supplementation that results in physiologic $25(\mathrm{OH}) \mathrm{D}$ levels in the mother and breastfeeding infant lead to any ill effects, as demonstrated by no change in vitamin $\mathrm{D}$ toxicity markers.
Maternal supplement breastfeeding infant even though both mothe $1000 \mathrm{IU}$ vitamin D/day. Group 3 No maternal supplementation; infants recieved 400 IU/day. Study 2: Group 1 Maternal supplement countries and that rickets may be an
High-dose supplementation of $4000 \mathrm{IU} /$ day and 6400 IU/day of vitamin D in healthy lactating mothers can increase the vitamin D concentration of milk to a level that supplies adequate vitamin $\mathrm{D}$ intake for the breastfeeding infant even though both mother and infant were limited in sunlight exposure. Vitamin D deficiency in exclusively breastfed infants appears to be an underdiagnosed public health problem in many underrepresentation of the magnitude of vitamin $\mathrm{D}$ deficiency. Multiple studies from the US and Europe show that supplementation of breastfeeding infants with $400 \mathrm{IU} /$ day of vitamin D is sufficient to prevent 


\section{Continued}

$2000 \mathrm{IU} /$ day (400 as $\mathrm{D}_{3}$ vitamin D deficiency when sun exposure is limited. It is and 1600 as $\mathrm{D}_{2}$ ). unknown whether such intake is adequate in Group 2 Maternal dark-skinned infants in parts of the world where there supplement 4000 is a high prevalence of severe vitamin D deficiency.

IU/day ( 400 as $\mathrm{D}_{3}$ and There is also poor compliance with vitamin $\mathrm{D}$ $3600 \mathrm{IU}$ as $\mathrm{D}_{2}$ ). supplementation of breastfeeding infants. The strategy Study 3: Group 1 of vitamin D supplementation of the breastfeeding Maternal supplement infant does not address the concomitant high $400 \mathrm{IU} \mathrm{D}_{3}$ /day; infants prevalence of vitamin D deficiency in their mothers. received $300 \mathrm{IU} \quad$ Maternal vitamin D supplementation of at least 2000 $\mathrm{D}_{3} /$ day. Group $2 \quad \mathrm{IU} /$ day is required to provide a significant amount of Maternal supplement vitamin D in the human milk for breastfeeding infants. $6400 \mathrm{IU} \mathrm{D}_{3}$ /day; $\quad$ Study 1 mothers who were supplemented with $2000 \mathrm{IU}$ infants received or $1000 \mathrm{IU}$ had significantly higher $25(\mathrm{OH}) \mathrm{D}(\mathrm{p}<$ placebo. 0.01 ). In Study 2, after 3 months of supplementation, the infants in the $2000 \mathrm{IU}$ group had significantly lower serum $25(\mathrm{OH}) \mathrm{D}_{2}$ levels than infants of mothers in the 4000 IU group ( $p=0.003$ ). In Study 3, after the 6 months of vitamin D supplementation, the mean ARA in milk was significantly higher in the 6400 IU group than the $400 \mathrm{IU}$ group ( $\mathrm{p}$ value not provided). Infants serum $25(\mathrm{OH}) \mathrm{D}$ were similar between groups: infants in the $400 \mathrm{IU}$ group was $43 \mathrm{ug} / \mathrm{L}$ at the end of the study compared to $46 \mathrm{ug} / \mathrm{L}$ in the $6400 \mathrm{IU}$ group. There was no evidence of toxicity in mothers or infants in either group.

Quality Rating Scale for Original Studies: Positive Quality-Most of the answers to the quality/validity questions were "yes" (including criteria 2, 3, 6, 7 and at least one other additional criterion); Neutral Quality-Answers on quality criteria 2, 3, 6, and 7 did not indicate that the study was exceptionally strong; Negative Quality-If six or more of answers on validity questions were no. Quality Rating Scale for Reviews: Positive Quality-if most of the answers on validity questions 1 - 4 were "yes"; Neutral Quality—if answers to any one of the first four validity questions was "no"; Negative Quality—if most (six or more) or the answers to validity questions are "no".

were supplemented with 1600 IU vitamin $\mathrm{D}_{2}$ plus $400 \mathrm{IU}$ vitamin $\mathrm{D}_{3}$ from a multivitamin. Mothers in this group exhibited decreased serum $\mathrm{D}_{3}(\mathrm{p}<0.02)$; a comparison group which received $3600 \mathrm{IU}$ vitamin $\mathrm{D}_{2}$ plus $400 \mathrm{IU}$ vitamin $\mathrm{D}_{3}$ demonstrated an increase in circulating total vitamin $\mathrm{D}$ species $(\mathrm{p}<0.06)$. Both groups had increased vitamin $\mathrm{D}_{2}(\mathrm{p}<0.0001 ; \mathrm{p}<0.04$, respectively). Total circulating $25(\mathrm{OH}) \mathrm{D}$ increased in group 1 mothers from $27.6 \pm 3.3$ to $36.1 \pm 2.3$ $\mathrm{ng} / \mathrm{mL}$ ( $\mathrm{p}<0.05$ ), compared to group 2 mothers whose circulating $25(\mathrm{OH}) \mathrm{D}$ increased from $32.9 \pm 2.4$ to $44.5 \pm 3.9 \mathrm{ng} / \mathrm{mL}$ ( $\mathrm{p}<0.04)$. Between groups, maternal $25(\mathrm{OH}) \mathrm{D}_{3}$ did not differ; however, $25(\mathrm{OH}) \mathrm{D}_{2}$ was significantly higher in the group receiving the larger dose of $\mathrm{D}_{2}(\mathrm{p}<0.01)$. Milk ARA was doubled in the first group from $35.5 \pm 3.5$ to $69.7 \pm 3.0 \mathrm{IU} / \mathrm{L}(\mathrm{p}<0.0001)$ compared with a much greater increase in those supplemented at the higher level in which the change was from $40.4 \pm 3.7$ to $134.6 \pm 48.3 \mathrm{IU} / \mathrm{L}$ ( $\mathrm{p}<0.0001$ ). In breastfed infants, vitamin $\mathrm{D}_{3}$ increased in both groups, from $7.9 \pm 1.1$ to $21.9 \pm 4.7 \mathrm{ng} / \mathrm{mL}$ (p $<0.02$ ) with the lower level supplement from $12.7 \pm 3.4$ to $18.8 \pm 4.1 \mathrm{ng} / \mathrm{mL}$ (p < $0.2)$. Vitamin $\mathrm{D}_{2}$ increased in both groups, the increase being twice as great in the infants whose mothers were supplemented at the higher level $(\mathrm{p}<0.0001)$. Total circulating $25(\mathrm{OH}) \mathrm{D}$ concentrations increased to the same extent in both groups. Although milk ARA never reached concentrations high enough to meet 
the DRI of 400 IU per day, infants in this study did not show signs of deficiency after 3 months of supplementation.

Basile et al. completed a similar randomized controlled trial using the same vitamin $\mathrm{D}_{2}$ and vitamin $\mathrm{D}_{3}$ intervention [3]. Researchers enrolled 25 fully breastfeeding mother-infant pairs. In the group receiving the lowest level of $\mathrm{D}_{2}$, maternal serum $\mathrm{D}_{2}$ increased from $22.4 \pm 8.8$ to $33.9 \pm 6.5(\mathrm{p}=0.002)$; and with the higher level of supplement, increased from $28.5 \pm 8.6$ to $43.0 \pm 11.6$ ( $\mathrm{p}=$ 0.0008). Between groups, the highest level supplement resulted in significantly higher serum 25(OH)D levels $(\mathrm{p}=0.03)$. Serum 25(OH)D levels increased in both groups of infants but infants breastfed by mothers given the highest level of $\mathrm{D}_{2}$ had significantly greater increases in serum 25(OH)D. Milk ARA was not measured in this study.

\subsection{Daily Vitamin D Supplementation Interventions}

In 2006, Wagner et al. studied 10 fully breastfeeding mother-infant pairs [11]. Mothers in Group 1 were supplemented with $400 \mathrm{IU}$ vitamin $\mathrm{D}_{3}$ and infants were supplemented with $300 \mathrm{IU}$ vitamin $\mathrm{D}_{3}$. In the second group, mothers were supplemented with $6400 \mathrm{IU}$ vitamin $\mathrm{D}_{3}$ and infants received a placebo. Of note, only four mother-infant pairs completed the entire study, but using an intent-to-treat approach, all 10 pairs were included in analysis. Total circulating 25(OH)D levels decreased in mothers in group 1 through visit 5; there was a slight improvement at visits 6 and 7 that corresponded to increased outdoor activities and sun exposure. Mothers in group 2 had an immediate increase in 25(OH)D levels that was sustained throughout the study period (significance not provided). Compared to group 1, the mean milk ARA in group 2 significantly increased to $873 \mathrm{IU} / \mathrm{L}(\mathrm{p}<0.0003)$, which resulted in a dramatic rise in infant circulating 25(OH)D levels. This rise in infant 25(OH)D was almost identical to that in the infants receiving $300 \mathrm{IU}$ per day vitamin $\mathrm{D}_{3}$ directly via oral supplementation.

Hollis et al. conducted a study of 95 fully breastfeeding mother-infant pairs in 2015 [13]. The intervention began with three groups: 400 IU vitamin $D_{3}$ for mothers plus $400 \mathrm{IU}$ vitamin $\mathrm{D}_{3}$ for infants; $2400 \mathrm{IU}$ vitamin $\mathrm{D}_{3}$ to mothers, placebo for infant; and $6400 \mathrm{IU}$ vitamin $\mathrm{D}_{3}$ for mothers, placebo to infants. Partway through the study, the 2400 IU group was discontinued due to safety concerns regarding low infant $25(\mathrm{OH}) \mathrm{D}$ levels. Therefore, only the $400 \mathrm{IU}$ group (group 1) and the $6400 \mathrm{IU}$ group (group 2) were included in analysis. Maternal 25(OH)D decreased $-10.5 \mathrm{nmol} / \mathrm{L}$ from visit $1(\mathrm{~V} 1)$ to visit 7 (V7) in group $1(\mathrm{p}$ $=0.02)$ and increased $+51.3 \mathrm{nmol} / \mathrm{L}$ in group 2 between V1 and V7 $(\mathrm{p}<0.0001)$. At V1, maternal 25(OH)D was similar between groups ( $\mathrm{p}=0.17)$; at V4, group 2 had significantly higher $25(\mathrm{OH}) \mathrm{D}(150.5 \pm 47.1 \mathrm{nmol} / \mathrm{L}$ compared to $83.0 \pm 29.1$ $\mathrm{nmol} / \mathrm{L}, \mathrm{p}<0.0001)$. At $\mathrm{V} 7$, group 2 continued to have significantly higher maternal 25(OH)D (151.2 $\pm 51.3 \mathrm{nmol} / \mathrm{L}$ compared to $79.0 \pm 31.3 \mathrm{nmol} / \mathrm{L},(\mathrm{p}<$ 0.0001). Infant $25(\mathrm{OH}) \mathrm{D}$ increased in both groups from V1 to V7 (Group 1: 36.0 
$\pm 26.1 \mathrm{nmol} / \mathrm{L}$ to $109.1 \pm 31.8 \mathrm{nmol} / \mathrm{L}$, significance not provided; Group 2: 41.0 $\pm 25.6 \mathrm{nmol} / \mathrm{L}$ to $108.5 \pm 38.0 \mathrm{nmol} / \mathrm{L}$, significance not provided). Between groups, there was no statistical significance at any time point (V1 $\mathrm{p}=0.35 ; \mathrm{V} 4 \mathrm{p}$ $=0.10 ; \mathrm{V} 7 \mathrm{p}=0.94)$. This suggests that high-dose maternal supplementation of 6400 IU vitamin $D_{3}$ daily is as effective as direct infant supplementation of 400 IU daily.

\subsection{Monthly Vitamin D Supplementation Interventions}

Wheeler, et al. completed a randomized controlled trial in 2016 with 87 exclusively breastfeeding mother-infant pairs in New Zealand [2]. Group 1 mothers received a placebo; Group 2 mothers received 50,000 IU vitamin $\mathrm{D}_{3}$ per month; and Group 3 mothers received 100,000 IU vitamin $\mathrm{D}_{3}$ per month. Vitamin D supplemented mothers had a significantly higher serum $25(\mathrm{OH}) \mathrm{D}$ concentrations at study end compared to placebo $(\mathrm{p}=0.043$ in group $2 ; \mathrm{p}=0.001$ in group $3)$. Infant change in serum $25(\mathrm{OH}) \mathrm{D}$ was not significantly different between groups ( $p=0.67$ in group $2 ; p=0.13$ in group 3 ). In group $1,26 \%$ of mothers exhibited vitamin D deficiency, compared to $4 \%$ of women in group 2, and $0 \%$ in group $3(\mathrm{p}=0.002)$. Deficiency rates between infants in all groups were simi$\operatorname{lar}(27 \%, 29 \%$, and $19 \%$, respectively; $\mathrm{p}=0.65)$

\subsection{Daily versus Monthly Vitamin D Supplementation}

Oberhelman, et al. conducted a randomized controlled trial of 40 exclusively breastfed mother-infant pairs to evaluate the difference between monthly supplementation with 150,000 IU vitamin D and daily supplementation with 5000 IU vitamin D per day for 1 month [4]. The monthly supplement was provided to mothers at study visits. Compliance with daily supplementation was monitored and found to be excellent (98\%). Those receiving the once monthly dose had significantly higher $25(\mathrm{OH}) \mathrm{D}$ concentrations than on days 1,3 , and 7 , but not on days 14 and 28 (significance not provided). With monthly supplementation, maternal $25(\mathrm{OH}) \mathrm{D}$ levels peaked on day 3 , and the maximum value observed in any mother was $72 \mathrm{ng} / \mathrm{mL}$. By day 28, the increase in 25(OH)D between baseline and day 28 was $11.9 \pm 4.2 \mathrm{ng} / \mathrm{mL}$ in those receiving the once monthly dose and $15.0 \pm 5.7 \mathrm{ng} / \mathrm{mL}$ with daily dosing. $(\mathrm{p}=0.06)$. None of the mothers' serum $25(\mathrm{OH}) \mathrm{D}$ concentrations remained $<20 \mathrm{ng} / \mathrm{mL}$ on day 28 (group 1 values: 43.9 $\pm 11.8 \mathrm{ng} / \mathrm{mL}$, range $22-71$; group 2 values: $41.2 \pm 8.9 \mathrm{ng} / \mathrm{mL}$, range $26-60$ $\mathrm{ng} / \mathrm{mL})$. Human milk cholecalciferol concentrations mirrored serum $25(\mathrm{OH}) \mathrm{D}$ concentrations, with peak values approximately $25 \%$ of serum values. By day 28 , serum $25(\mathrm{OH}) \mathrm{D}$ levels increased in the infants of both groups and all infants achieved a serum $25(\mathrm{OH}) \mathrm{D}$ concentration $>20 \mathrm{ng} / \mathrm{mL}$. However, increases in infant's $25(\mathrm{OH}) \mathrm{D}$ levels did not directly correlate with maternal increases in maternal 25(OH)D ( $\mathrm{r}=0.07, \mathrm{p}=0.64)$. A recent study $(\mathrm{Nalk}, 2017)$ evaluated effectiveness of maternal supplementation with 600,000 IU vitamin D in divided doses over 10 days in the early postpartum period on maternal and infant serum 
$25(\mathrm{OH}) \mathrm{D}$ levels and measures of rickets in exclusively breastfed infants. Maternal 25(OH)D levels after 6 months of study were greater $40.3 \pm 21.6 \mathrm{ng} / \mathrm{mL}$ in supplemented vs $22.9 \pm 20.18 \mathrm{ng} / \mathrm{mL}$ in controls. Infant levels were also higher $(29.29 \pm 14.67 \mathrm{ng} / \mathrm{mL})$ in those fed by supplemented mothers and $15.73 \pm 17.73$ $\mathrm{ng} / \mathrm{mL}$ in controls. After 6 months of exclusive breastfeeding, only one mother and four infants had serum $25(\mathrm{OH}) \mathrm{D}$ levels $<11 \mathrm{ng} / \mathrm{ml}$ in the supplemented group $(n=53)$ vs 9 mothers and 25 infants $(n=57)$ in the control. Although 2 infants in each group developed clinical rickets. This study suggests that large divided doses may be effective in preventing vitamin $\mathrm{D}$ deficiency in mothers and infants during the first six months of breastfeeding [19].

\section{Discussion}

Healthy people 2020 set a breastfeeding target of $81.9 \%$ of infants "ever being breastfed" [17]. Breast milk is considered to be the gold-standard for infant nutrition, providing all the nutrients the young infant requires. It is therefore important to evaluate whether the adequacy of Vitamin D in breast milk can be insured through maternal intake.

The results of the available studies demonstrate that high-dose daily maternal vitamin D supplementation (ranging from 4000 IU to $6000 \mathrm{IU} /$ day) during lactation is effective in improving both maternal and infant vitamin $\mathrm{D}$ status. Monthly supplementation at levels of 150,000 IU corrected both maternal and infant deficiency but not at lower levels (50,000 IU and 100,000 IU). This is likely because cholecalciferol is quickly converted to $25(\mathrm{OH}) \mathrm{D}$ by the mother; cholecalciferol is the main form of vitamin D transferred into human milk [1] [4]. Therefore, daily supplementation may be preferred to optimize infant vitamin D status. There is some concern surrounding compliance. Mothers who received monthly vitamin D supplementation in the reviewed studies were administered their dose on-site; mothers who received daily supplementation were largely responsible for their own administration. An unrelated study in Japan found that monthly dosing of bisphosphonates for osteoporosis had higher compliance compared to daily and weekly dosing [18]. Additional studies assessing compliance in relation to maternal self-administered vitamin D supplementation need to be conducted to confirm these results. Previous studies demonstrate that vitamin $\mathrm{D}_{3}$ is more bioavailable than vitamin $\mathrm{D}_{2}$; [6] [7] [11] this needs to be confirmed in the current context as studies with varying types of vitamin $\mathrm{D}$ did not assess similar doses.

Limitations of the research to support the question of vitamin D supplementation is a general lack of standards for acceptable levels of serum $25(\mathrm{OH}) \mathrm{D}$, the diagnosis of vitamin $\mathrm{D}$ insufficiency and vitamin $\mathrm{D}$ deficiency. The studies were heterogeneous with respect to intervention protocol, timing and levels of supplementation. Additional studies assessing safety of long-term, high-dose vitamin D supplementation are warranted. The longest study follow-up was 7 months, the effects of longer term supplementation on infant outcomes and ma- 
ternal and infant toxicity are lacking.

\section{Conclusion}

Seven randomized controlled trials and four reviews demonstrate that maternal supplementation of vitamin D may be an effective method of improving breastfed infants' vitamin D status. However, there is no consensus as to which dose is ideal, both in timing (monthly versus daily) and quantity. This is further compounded by the fact that there is no agreement on the classification of vitamin $\mathrm{D}$ deficiency on the basis of serum $25(\mathrm{OH}) \mathrm{D}$ levels. Furthermore, the dose apparently necessary to correct both the mother's and infant's vitamin D status is well above the Adequate Intake of $600 \mathrm{IU}$ per day. In fact, the Tolerable Upper Limit is set at $4000 \mathrm{IU}$ during lactation, which appears to be the minimum dose necessary to meet the nursing infant's vitamin $\mathrm{D}$ needs. The Food and Nutrition Board of the National Academies of Science, Engineering, and Medicine should consider revising the Dietary Reference Intakes for vitamin D, given the evidence that higher doses show no signs of adverse events and are necessary to meet the vitamin D needs of both the mother and infant. Additionally, the AAP should likewise consider revising their statement on infant supplementation of vitamin $\mathrm{D}$ to include high-dose maternal supplementation of approximately 4000 IU per day as adequate in lieu of direct infant supplementation. Ideally, further studies evaluating the ideal dose and confirming other studies' results should be conducted. It appears that daily dosing is the most effective method for improving both maternal and infant vitamin D status. Based on this evidence, practitioners may confidently recommend maternal-only supplementation of vitamin $\mathrm{D}$ at a minimum dose of $4000 \mathrm{IU}$ per day.

\section{Conflicts of Interest}

The authors declare no conflicts of interest regarding the publication of this paper.

\section{References}

[1] Thiele, D.K., Senti, J.L. and Anderson, C.M. (2013) Maternal Vitamin D Supplementation to Meet the Needs of the Breastfed Infant: A Systematic Review. Journal of Human Lactation, 29, 163-170. https://doi.org/10.1177/0890334413477916

[2] Wheeler, B.J., Taylor, B.J., Herbison, P., et al. (2016) High-Dose Monthly Maternal Cholecalciferol Supplementation during Breastfeeding Affects Maternal and Infant Vitamin D Status at 5 Months Postpartum: Arandomized Controlled Trial. The Journal of Nutrition, 146, 1999-2006. https://doi.org/10.3945/jn.116.236679

[3] Basile, L.A., Taylor, S.N., Wagner, C.L., Horst, R.L. and Hollis, B.W. (2006) The Effect of High-Dose Vitamin D Supplementation on Serum Vitamin D Levels and Milk calcium Concentration in Lactating Women and Their Infants. Breastfeeding Medicine, 1, 27-35. https://doi.org/10.1089/bfm.2006.1.27

[4] Oberhelman, S.S., Meekins, M.E., Fischer, P.R., et al. (2013) Maternal Vitamin D Supplementation to Improve the Vitamin D Status of Breastfed Infants: A Randomized Controlled Trial. Mayo Clinic Proceedings, 88, 1378-1387. 
https://doi.org/10.1016/j.mayocp.2013.09.012

[5] Dawodu, A. and Tsang, R.C. (2012) Maternal Vitamin D Status: Effect on Milk Vitamin D Content and Vitamin D Status of Breastfeeding Infants. Advances in $\mathrm{Nu}$ trition, 2012, 353-361. https://doi.org/10.3945/an.111.000950

[6] Haggerty, L.L. (2011) Maternal Supplementation for Prevention and Treatment of Vitamin D Deficiency in Exclusively Breastfed Infants. Breastfeeding Medicine, 6, 137-144. https://doi.org/10.1089/bfm.2010.0025

[7] Taylor, S.N., Wagner, C.L. and Hollis, B.W. (2008) Vitamin D Supplementation during Lactation to Support Infant and Mother. The Journal of the American College of Nutrition, 27, 690-701. https://doi.org/10.1080/07315724.2008.10719746

[8] Vitamin D: Fact Sheet for Health Professionals. NIH Office of Dietary Supplements. https://ods.od.nih.gov/factsheets/VitaminD-HealthProfessional/

[9] Looker, A.C., Johnson, C.L, Lacher, D.A., Pfeiffer, C.M., Schleicher, R.L. and Sempos, C.T. (2011) Vitamin D status: United States, 2001-2006. Centers for Disease Control and Prevention. https://www.cdc.gov/nchs/products/databriefs/db59.htm

[10] Choi, Y.J., Kim, M.K. and Jeong, S.J. (2013) Vitamin D Deficiency in Infants Age 1 to 6 Months. Korean Journal of Pediatrics, 56, 205-210. https://doi.org/10.3345/kjp.2013.56.5.205

[11] Wagner, C.L., Hulsey, T.C., Fanning, D., Ebeling, M. and Hollis, B.W. (2006) High-Dose Vitamin $\mathrm{D}_{3}$ Supplementation in a Cohort of Breastfeeding Mothers and Their Infants: a 6-Month Follow-Up Pilot Study. Breastfeeding Medicine, 1, 59-70. https://doi.org/10.1089/bfm.2006.1.59

[12] Hollis, B.W. and Wagner, C.L. (2004) Vitamin D Requirements During Lactation: High-Dose Maternal Supplementation as Therapy to Prevent Hypovitaminosis D for Both the Mother and the Nursing Infant. The American Journal of Clinical Nutrition, 80, 1752S-1758S. https://doi.org/10.1093/ajcn/80.6.1752S

[13] Binkly, N., Kruegen, D., Cowgill, C.S., Plum, L., Lake, E., Hansen, K.E., DeLuca, H.F. and Drezner, M.K. (2004) Assay Variation Confounds the Diagnosis of Hypovitaminosis D: A Case for Standardization. The Journal of Clinical Endocrinology \& Metabolism, 89, 3152-3157. https://doi.org/10.1210/jc.2003-031979

[14] Bi, W.G. and Nuyt, A.M. (2018) Association between Vitamin D Supplementation during Pregnancy and Offspring Growth, Morbidity Andmortality. A Systematic Review and Meta-Analysis. JAMA Pediatrics. https://doi.org/10.1001/jamapediatrics.2018.0302

[15] Academy of Nutrition and Dietetics Research and Sategic Business Department. Evidence Analysis Library Manual, 2012, Chicago.

[16] Hollis, B.W., Wagner, C.L., Howard, C.R., et al. (2015) Maternal versus Infant Vitamin D Supplementation during Lactation: A Randomized Controlled Trial. Pediatrics, 136, 625-634. https://doi.org/10.1542/peds.2015-1669

[17] Maternal, Infant, and Child Health. Healthy People 2020. Accessed 8/22/2018. https://www.healthypeople.gov/2020/topics-objectives/topic/maternal-infant-and-c hild-health/objectives

[18] Kishimoto, H. and Maehara, M. (2015) Compliance and Persistence with Daily, Weekly, and Monthly Bisphosphonates for Osteoporosis in Japan: Analysis of Data from the CISA. Archives of Osteoporosis, 10, 27. https://doi.org/10.1007/s11657-015-0231-6

[19] Nalk, P., Faridi, M.M.A., Batra, P. and Madhu, S.V. (2017) Oral Supplementation of Parturient Mothers with Vitamin D and Its Effect on 25OHD Status of Exclusively 
Breastfed Infants at 6 Months of Age: A Double-Blind Randomized Placebo Controlled Trial. Breastfeeding Medicine, 12, 621-629.

https://doi.org/10.1089/bfm.2016.0164 